\title{
Biotreatment Effects in Films and Blends of PVC/PCL Previously Treated with Heat
}

\author{
Adriana de Campos and Sandra Mara Martins Franchetti* \\ Universidade Estadual Paulista - UNESP; Instituto de Biociências; Departamento de Bioquímica e Microbiologia; \\ Av. 24 A, no 1515; Caixa Postal 199; 15.306-900; Rio Claro - SP - Brazil
}

\begin{abstract}
Studies were carried out on biomodification and the pre-heat $\left(130^{\circ} \mathrm{C}\right)$ influence on Poly (vinyl chloride) / Poly (E-caprolactone) films. The results showed that heat pre-treatment improved the biomodification of PVC films, but it inhibited the biomodification of the PVC/PCL film.
\end{abstract}

Key words: Biotreatment, thermal treatment, UV-Visible, PVC/PCL Blend

\section{INTRODUCTION}

Plastic use for packaging materials has increased rapidly over the last 20 years. The annual disposal of plastics has raised the demand for nondegradable plastic materials. Selective use of biodegradable polymers in certain applications might help to reduce the environmental impact of plastic materials (Yavuz et al., 2002). These materials became a waste concern, because of their persistence in the environment (Aboud-Zeid et al., 2001).

Poly( $\varepsilon$-caprolactone) (PCL) an aliphatic polyester is derived from a ring opening polymerization of $\varepsilon$-caprolactone, and has a relatively low melting point, $60^{\circ} \mathrm{C}$ (Darwis et al., 1999). Biocompatible, biodegradable and non-toxic synthetic aliphatic polyesters in biomedical applications are especially used as drug delivery devices, because when inside of the body they are completely degradable. An interesting property of PCL (a good example of an aliphatic polyester) is its

\footnotetext{
* Author for correspondence
}

ability to form compatible blends with a wide range of other polymers (Darwis et al., 1999).

Polyvinyl chloride (PVC) is one of the most important commodity plastics in use nowadays (Varma et al., 1999). It is often used as food packaging, toys, pipes, floor, window frames, etc (Anon, 1997). PVC, a known thermal and photo unstable polymer, degrades over $130^{\circ} \mathrm{C}$ (Pospisil et al., 1999; Veronelli et al., 1999). The photo and thermal degradation releases hydrochloric gas (dehydrochlorination) that leads to the formation of conjugate polyene sequences $(-\mathrm{CH}=\mathrm{CH})$ in the polymer chains, giving the $\mathrm{PVC}$ a reddish brown color (Hollande and Laurent, 1997; Veronelli et al., 1999).

The polymer surface deterioration is an interfacial process. It can involve microorganisms that can colonize the polymer surfaces as biofilms. These biofilms consist of cells embedded in a polymer matrix of their own origin, containing polysaccharides and proteins (Flemming, 1998; Costerton et al., 1987). Some of the major ways through which microorganisms deteriorate synthetic polymers are: fouling, which is an 
unwanted deposition and growth of microorganisms on surfaces; degradation of leaching components; corrosion including hydration, penetration, and color change due to biofilms which can contain organisms that produce pigments (Flemming, 1998).

Some fungi, such as Phanerochaete chrysosporium and Aspergillus fumigatus are known for their ability to degrade some recalcitrant pollutants such as synthetic polymers. The former is called white rot fungus and degrades lignin and synthetic polymers (Martins et al., 2001; Thomas et al., 1992; Lymar et al., 1995) and the latter has been described as an effective degrader of plasticized PVC and DDT. Scanning Electronic Microscopy (SEM) studies with this fungus on poly-hydroxybutirate-co-valerate samples showed degradation on their surfaces (Renstad et al., 1999).

Polyesters are potentially biodegradable due to the hydrolysable ester bonds. PCL mixed with PVC alters its properties, such as high impact behavior, heat resistance temperature and technological processing. PCL was reported to be a very effective plasticizer for PVC (Karal et al., 1997). In some cases, thermal and photo pre-treatment can facilitate the attack of microorganisms on the polymer surface (Veronelli et al., 1999). The literature did not show any paper that uses thermal and biological treatment on PVC/PCL films.

In this paper, we intended to associate thermal and biological treatments on PVC/PCL blend using UV-Visible absorption spectroscopy to find out evidences of deterioration.

\section{MATERIALS AND METHODS}

\section{Chemicals}

Poly(E-caprolactone) (Fig. 1) was kindly supplied by the Department of Engineering Materials UFSCar - São Carlos, SP, Brazil. Poly(vinyl chloride) (Fig. 2) M $\mathrm{M}=145,636 \mathrm{~g} / \mathrm{mol}$ (PVC) Norvic, without additives, was supplied by the Petrochemistry Company of Camaçari, Bahia, Brazil. As solvent, 1,2-dichloroethane, p.a. (Reagen) was used as received.

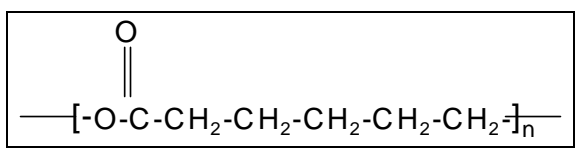

Figure 1 - Poly $(\varepsilon$-caprolactone) (PCL)

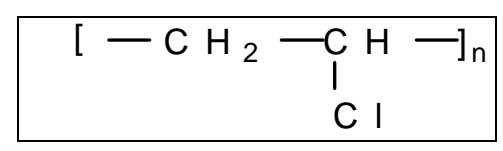

Figure 2 - Poly( vinyl chloride) (PVC)

\section{Fungi}

Phanerochaete chrysosporium (CCB 478) was supplied by the Mycology and Liquenology section of the Botany Institute, Brazil. Aspergillus fumigatus was isolated as a contaminant of some culture media in the Laboratory of Polymers of the Biochemistry and Microbiology Department, UNESP, Rio Claro, SP, Brazil.

\section{Sample Preparation}

Films of PVC, PCL and blends of PVC/PCL 1:1 were obtained by casting from solutions of PVC and PCL in dichloroethane on a glass plate, whose diameter was $2.5 \mathrm{~cm}$ at room temperature $\left(25^{\circ} \mathrm{C}\right)$. The films were dried under vacuum for 48 hours (Martins-Franchetti et al., 2002).

\section{Thermal pre-treatment}

Films of PVC, PCL films and the blends of polymers were thermally treated in a high power oven $\left(130^{\circ} \mathrm{C}\right)$ for one hour before the microbial treatment.

\section{Fungi suspension preparation}

$P$. chrysosporium and A. fumigatus were grown in slants at room temperature. The suspension was obtained by adding $9.0 \mathrm{~mL}$ of saline solution $0.85 \%(\mathrm{~m} / \mathrm{v})$ in the slants, and afterwards filtering it in glass wool. The liquid suspension obtained containing fungi spores was used as inoculum.

\section{Culture Medium}

The liquid culture medium consisted of a solution of Sabouraud - Malt. P.chrysosporium and A. fumigatus were inoculated $(1 \mathrm{~mL}$ removed from saline suspension) in the culture medium and kept for 7 days at $32^{\circ} \mathrm{C}$ without films.

\section{Microbial treatment of the films}

Duplicate samples of PVC, PCL and PVC/PCL 1:1 were incubated in Sabouraud -Malt solution in $500 \mathrm{~mL}$ Erlenmeyer flasks containing $100 \mathrm{~mL}$ of Saboraud-malt medium with $P$. chrysosporium and A. fumigatus. The original films (without any treatment) and heat pre-treated films were kept for 4 months, in a incubator at $32^{\circ} \mathrm{C}$ without agitation. 
After this treatment, all films were washed several times with distilled water and dried under vacuum for 48 hours.

\section{UV-Visible spectroscopy (UV-Vis.)}

UV-Vis. spectra were obtained on a UV-Vis. Shimadzu spectrometer (UV-2401 model) in a range of 200-800nm.

\section{RESULTS AND DISCUSSION}

PVC, PCL and PVC/PCL 1:1 films were colorless and transparent films, with $30 \mu \mathrm{m}$ thicknesses. After thermal treatment, these films changed to a pink color suggesting degradation. UV-Vis spectra of the PVC films thermally treated revealed the presence of polyenes in the range of $450-650 \mathrm{~nm}$ (Fig.3). This result was in accordance with the thermal degradation mechanism of PVC, described by Veronelli et al. (1999).

Spectra of biotreated PVC films showed an increase of the absorbance intensity, because the film became opaque (Fig. 4). Spectra of heat pretreated and biotreated PVC films presented an increase of the absorbance intensity in the range of 450-650 $\mathrm{nm}$ wich was attributed to the absorption of polyenes sequences on PVC matrix (Fig.5). In this case, the biotreatment was effective only after the thermal treatment.
The UV-Vis. spectrum of PCL did not present significant changes after thermal treatment (Fig. 6). Biotreated PCL films showed an increase of the absorption intensity in the range of 260-340 $\mathrm{nm}$, related to carbonyl groups (Fig. 7). The UVVis spectra of the thermal and biotreated PCL film showed a significant increase of the absorbance intensity of carbonyl groups $(260-340 \mathrm{~nm})$ and the presence of three sharp bands related the absorption of different types of carbonyl groups (Fig. 8). In this case, it was difficult to say whether the modification on PCL film was more or less important than just in the case of the biotreatment. The UV-Vis. spectrum of the PVC/PCL 1:1 blend did not present changes after thermal treatment (Fig. 9). This showed the PCL effect in PVC chains, which in this case, did not undergo thermal degradation, as in the PVC film. The biotreated blend showed three sharp bands related to the absorption of the carbonyl groups on UV-Vis. spectroscopy (Fig. 10). The UV-Vis. spectrum of the thermal biotreated blend (Fig.11) showed that the bands of carbonyl groups and polyenes decreased (260-340 $\mathrm{nm}$ and 450-650 nm, respectively) in comparison to the $\mathrm{PVC}$ spectrum (Fig. 5). It seemed that the PCL protected the thermal degradation of the $\mathrm{PVC}$ and the PVC protected the biodegradation of the PCL, i.e. the $\mathrm{C}=\mathrm{O}$ groups of $\mathrm{PCL}$ interacted with the $\mathrm{H}-\mathrm{C}-\mathrm{Cl}$ groups of PVC, avoiding the thermal and biodegradation in both the polymers.

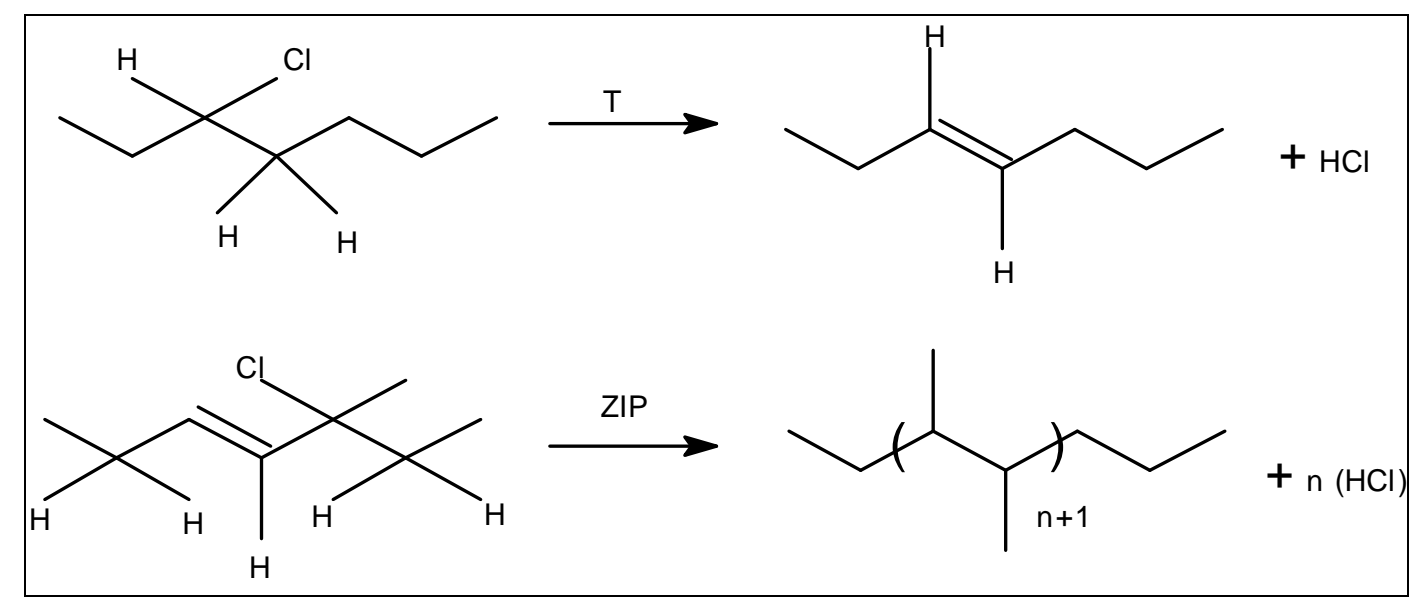

Scheme 1 - Dehydrochlorination reactions in PVC macromolecules (Veronelli et al., 1999). 
The protection effect in the PVC/PCL blend was investigated by Karal et al (1997), but the effect was noticed in the thermal and the biodegradation processes of the blend. The thermal degradation mechanisms of both individual polymers were previously described by Kaczmarek et al. (2002). The effect of the PCL on the thermal oxidative degradation of the PVC could be explained by the combined reactions between the active groups formed in degraded PVC $\left({ }^{\circ} \mathrm{CH}_{3},{ }^{\circ} \mathrm{CH}_{2} \mathrm{CH}_{2}\right.$, ${ }^{\circ} \mathrm{CH}_{3} \mathrm{Cl}$ ) and PCL chains (Kaczmarek et al., 2002). Thermal degradation (at $130^{\circ} \mathrm{C}$ ) created double bonds in PVC (evolution of $\mathrm{HCl}$ ), by "zip" dehydrochlorination (Scheme1) (Veronelli et al., 1999).

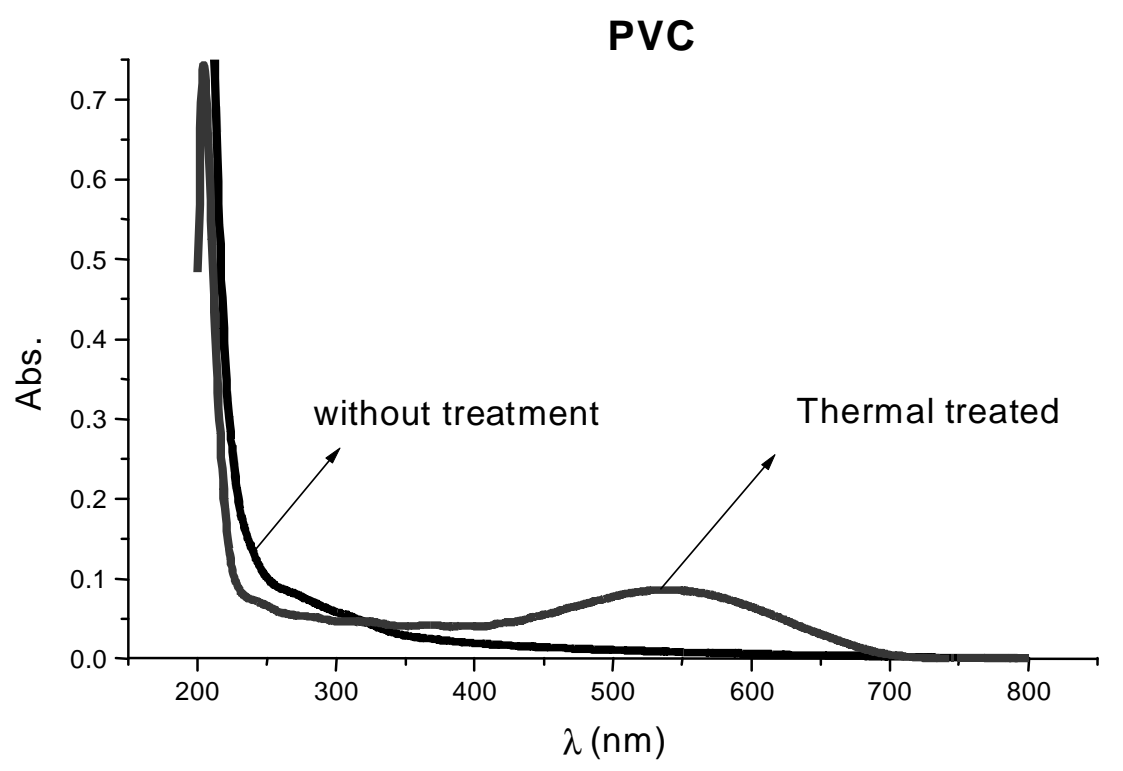

Figure 3 - UV-Vis Absorption spectra of PVC films without treatment, heat pre-treated $\left(130^{\circ} \mathrm{C}\right)$

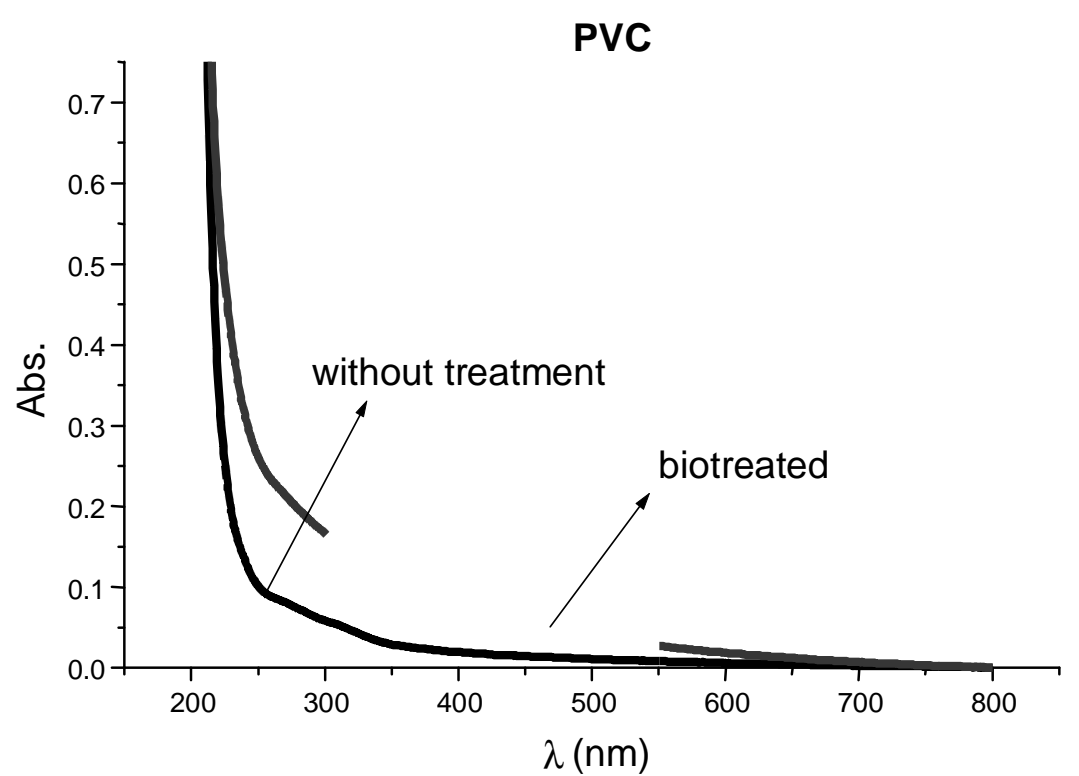

Figure 4 - UV-Vis Absorption spectra of PVC films without treatment, biotreated with P. chrysosporium/A. fumigatus 


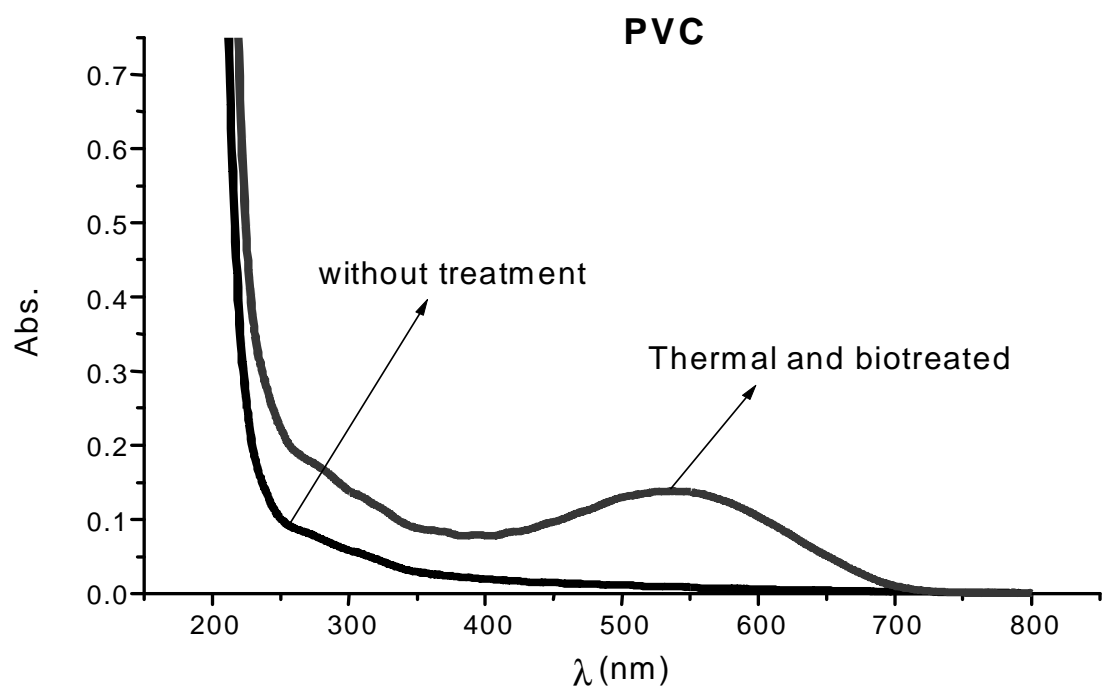

Figure 5 - UV-Vis Absorption spectra of PVC films without treatment, thermal and biotreated with $P$. chrysosporium/A. fumigatus

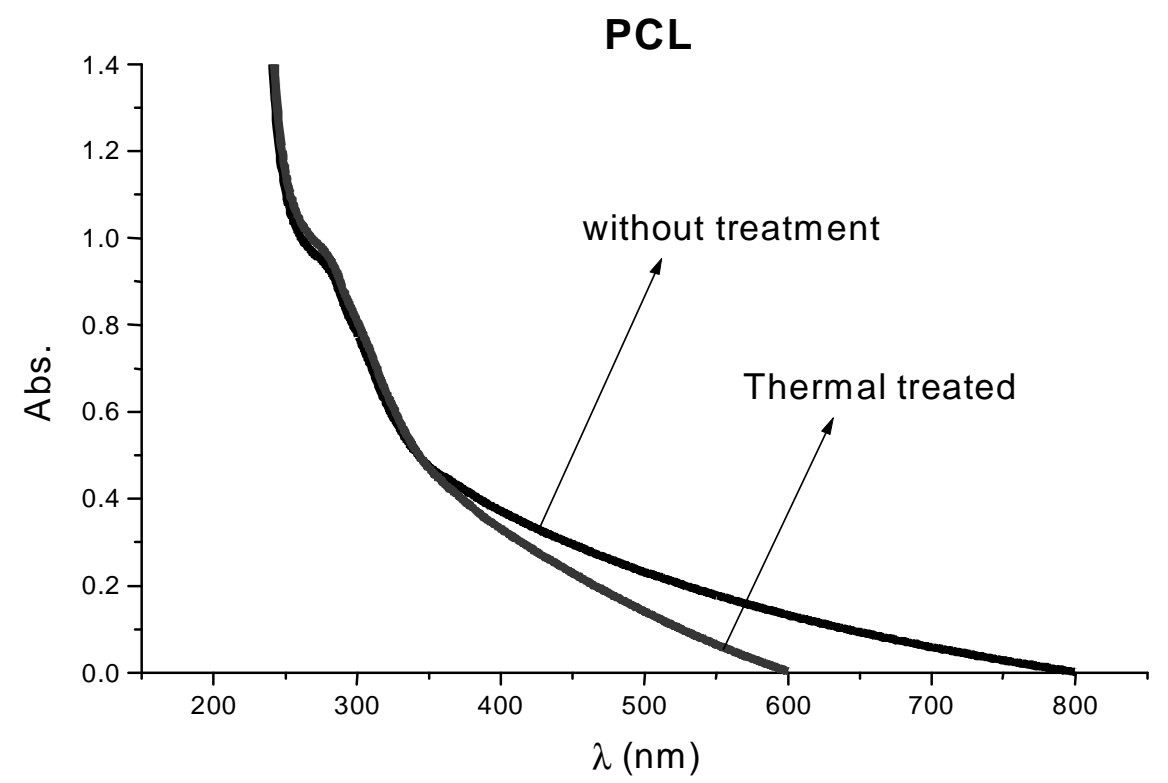

Figure 6 - UV-Vis Absorption spectra of PCL films without treatment, heat pre-treated $\left(130^{\circ} \mathrm{C}\right)$ 


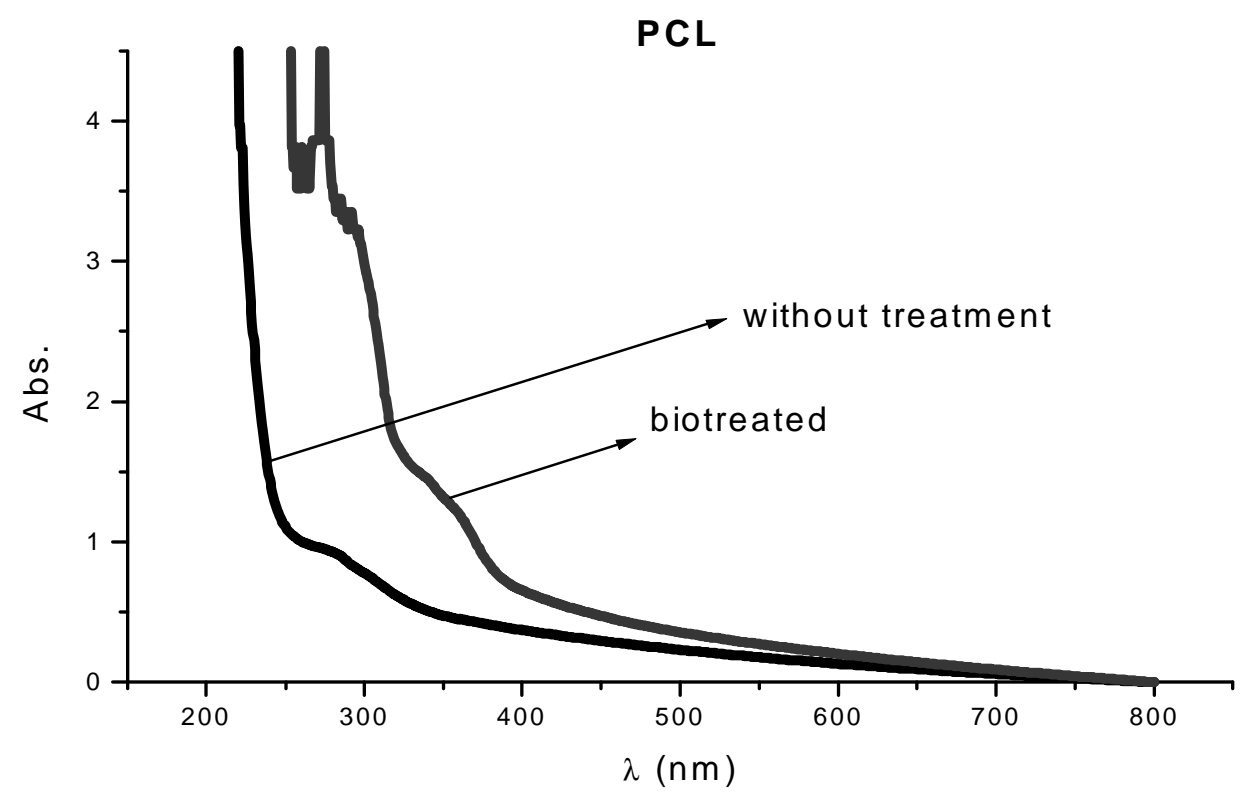

Figure 7 - UV-Vis Absorption spectra of PCL films without treatment, biotreated with P. chrysosporium/A. fumigatus

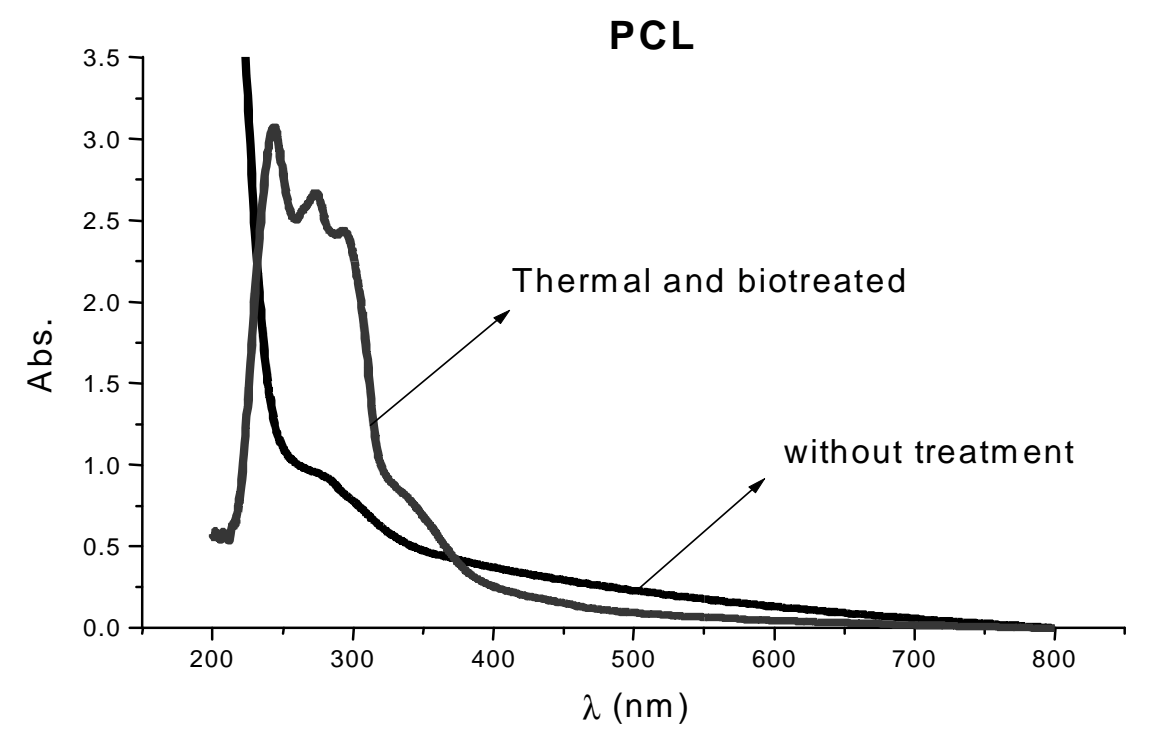

Figure 8 - UV-Vis Absorption spectra of PCL films without treatment

_ thermal and biotreated with P. chrysosporium/A. fumigatus 


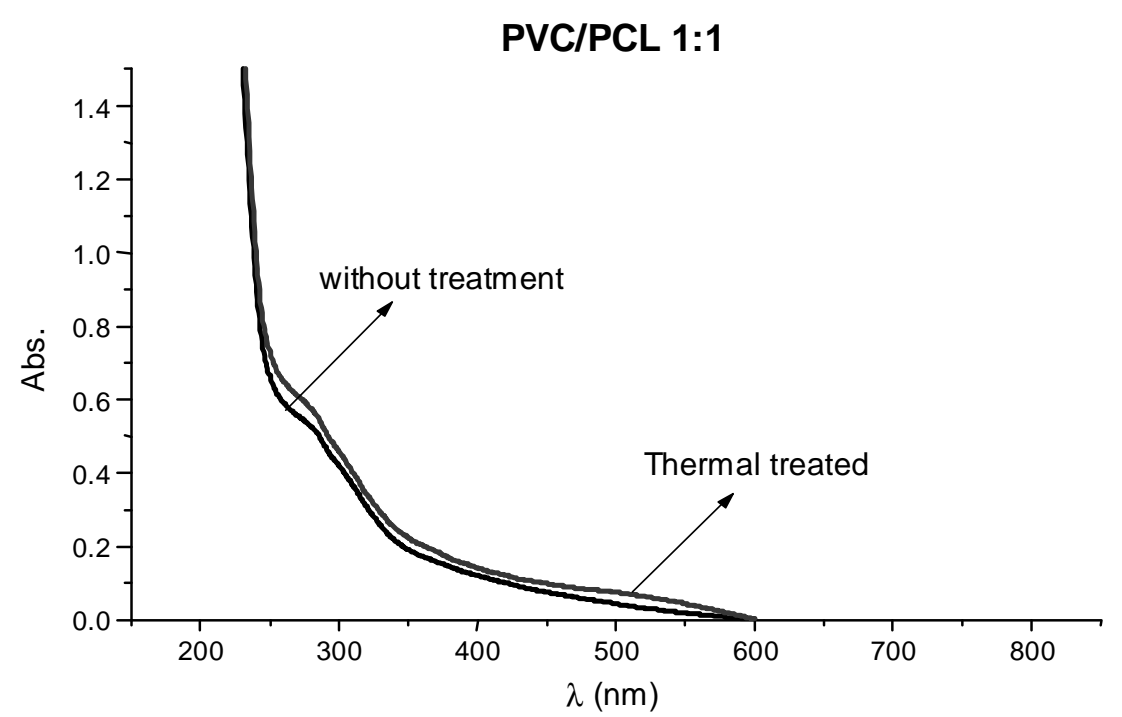

Figure 9- UV-Vis Absorption spectra of PVC/PCL 1:1 films without treatment, heat pretreated $\left(130^{\circ} \mathrm{C}\right)$

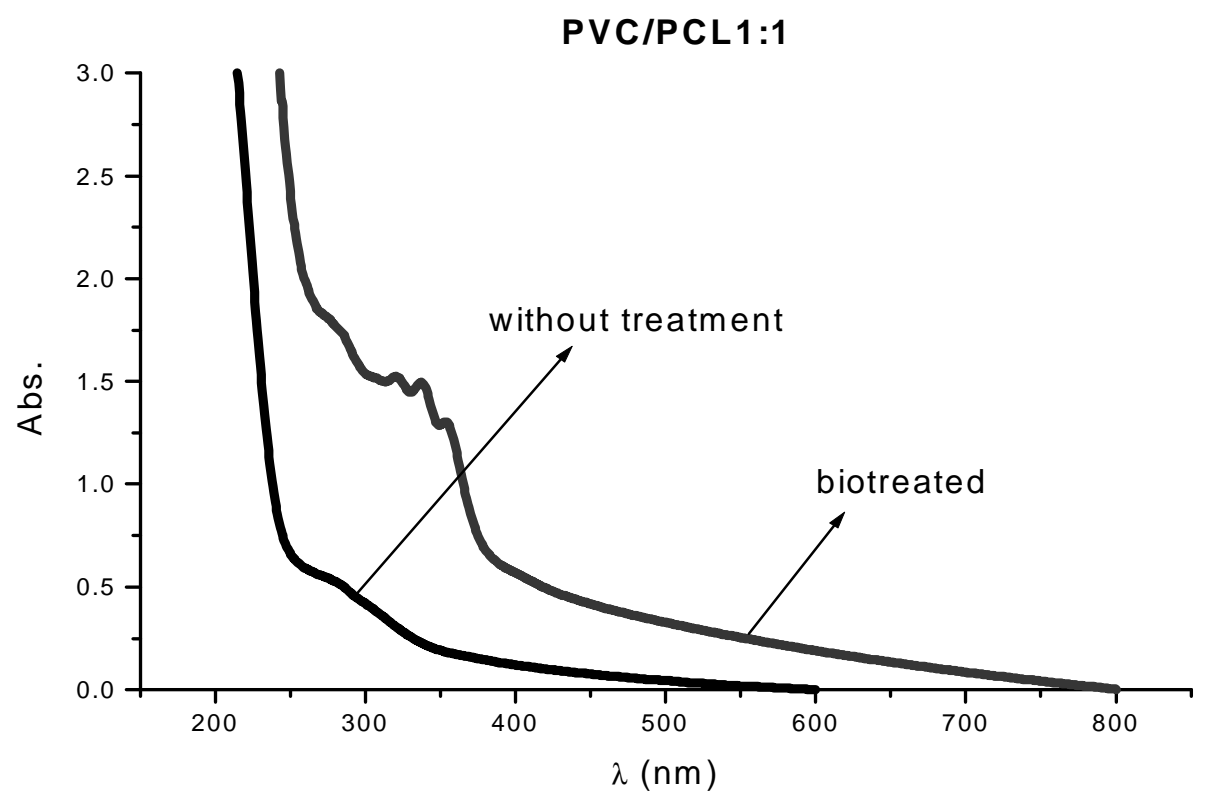

Figure 10 - UV-Vis Absorption spectra of PVC/PCL 1:1 films without treatment, biotreated with $P$. chrysosporium/A fumigatus 


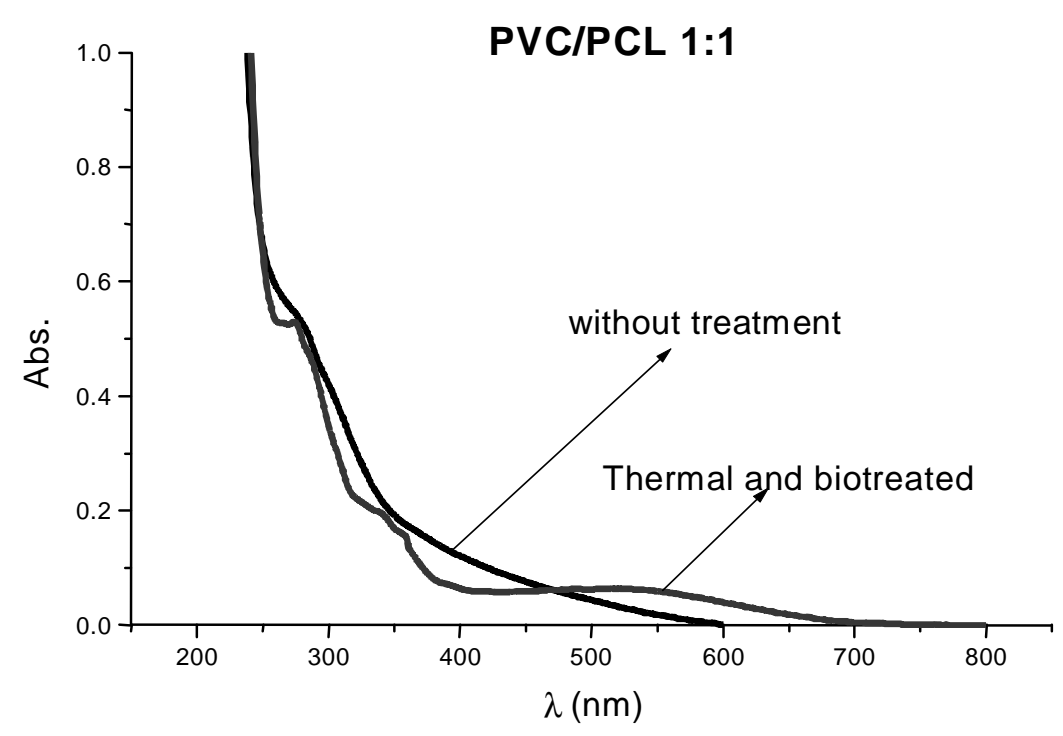

Figure 11 - UV-Vis Absorption spectra of PVC/PCL 1:1 films without treatment, thermal and biotreated with $P$. chrysosporium/A. fumigatus

\section{CONCLUSION}

The thermal effect on biotreatment was effective in isolated PCL and PVC films, but in the PVC/PCL blend this effect was non-significant. The pre-heat treatment, in these experimental conditions, inhibited the biomodification of the blend. Regarding the PVC/PCL blend it could be concluded that PCL avoided both the thermal degradation and the thermal biodegradation of PVC. This could be attributed to the interaction between carbonyl groups of the PCL and H-C-Cl groups of the PVC.

\section{ACKNOWLEDGEMENTS}

This work was supported by the FAPESP (Fundação de Amparo à Pesquisa do Estado de São Paulo) under grant 02/12081-0. We are grateful to Prof. José Augusto Agnelli from (DEMA) UFSCar-São Carlos-SP, Brazil. We wish to thank Jonathan and Cybel Burgess for English review.

\section{RESUMO}

Poli ع-caprolactona é um importante polímero biodegradável e miscível com o PVC, um polímero sintético industrial, termo susceptível e não biodegradável. A blenda PVC/PCL é importante quanto a suas propriedades mecânicas e biodegradabilidade. Neste trabalho foi analisada a biomodificação da blenda PVC/PCL pré-tratada com calor $\left(130^{\circ} \mathrm{C}\right)$, através da espectroscopia UVVis. Os resultados mostraram que o pré-tratamento com calor pode facilitar a biomodificação em filmes de PVC, mas pode inibir a biomodificação nos filmes da blenda PVC/PCL.

\section{REFERENCES}

Abou-Zeid D. M.; Muller, R. J. and Deckwer, W. D. (2001), Degradation of natural and synthetic polyester under anaerobic conditions. J. Biotechnol., 86, 113-126.

Anon (1997), Curso básico intensivo de plásticos (CBIP). Jornal de plásticos, 35-47.

Costerton, W. J.; Cheng, K. J.; Geesey, G. G.; Ladd, T. J.; Nickel, J. C.; Dasgupta, M. and Marrie, T. J. (1987). Ann. Ver. Microbiol., 41, 435. 
Darwis, D.; Mitomo, H. and Yoshii, F. (1999), Degradability of radiation crosslinked PCL in the supercooled state under various environments. Polym. Degrad. Stabil., 65, 279-285.

Flemming, H. D. (1998), Relevance of biofilms for the biodeterioration of surfaces of polymeric materials. Polym. Degrad. Stabil., 59, 309-315.

Hollande, S. and Laurent, J. L. (1997), Study of discolouring change in PVC, plasticizer and plasticized PVC films. Polym. Degrad. Stabil., 55,141-145.

Honda, Y. and Osawa, Z. (2002), Microbial denitrication of wastewater using biodegradable polycaprolactone. Polym. Degrad. Stabil., 76, 321-327.

Karal, O.; Hamarcu, E. and Baysal, B. M. (1997), Blends of caprolactone - poly (dylimetylsiloxane) polycaprolactone triblock copolymer with poly (vinyl chloride): preparation and characterization. Polym. Degrad. Stabil ,38, 6071-6078.

Kaczmarek, H.; Drag, R.; Swiatek, M. and Oldak, D. (2002), The influence of UV-irradiation on poly (vinyl chloride) modified by poly (vinyl acetate). Surface Science, 507-510, 877-882.

Lymar, E. S.; Li, B. and Renganathan, V. (1995), Purification and characterization of a cellulosebinding $\beta$-glucosidase from cellulose-degrading cultures of Phanerochaete chrysosporium. Applied and environmental microbiology, 61 : (8), 2976-2980.

Martins, M. A. M.; Ferreira, I. C.; Santos, I. M.; Queiroz, M. J. and Lima, N. (2001), Biodegradation of bioaccessible textile azo dyes by Phanerochaete chrysosporium. J. Biotech., 89, 91-98.

Martins-Franchetti, S. M.; Silva, E. R. and Trombini, R. C. (1999), Biotransformation of PVC films by liquid waste from landfill, Arq. Inst. Biol., 66 : (2), 133-136.

Martins-Franchetti, S. M.; Domingos, R. N. and Trombini, R. C. (2002), Modifications on PVC films by ultrasound. Ultrasonics sonochemistry, 9, 139-141.

Pospisil, J. (1999), Degradation and aging of polymers blends. Thermomechanical and thermal degradation. Polym. Degrad. Stabil., 65, 405-414.
Renstad, R.; Karlsson, S. and Albertsson, A. C. (1999), The influence of processing induced differences in molecular structure on the biological and nonbiological degradation of poly (3-hydroxybutyrate-co3-hydroxyvalerate, $\mathrm{P}(3-\mathrm{HB}-\mathrm{co} 03-\mathrm{HV}), \mathbf{6 3}, 201-211$.

Thomas, D. R.; Carswell, K. S. and Georgiou, G. (1992), Mineralization of biphenyl and PCBs by the white rot fungus Phanerochaete chrysosporium. Biotechnology and bioengineering, 40, 11, 1395-1402.

Varma, A. J.; Despande, S. V. and Kondapalli, P. (1999), a comparative study of thermal behavior of PVC, a series of synthesized chlorinated polyethylenes and HDPE. Polym. Degrad. Stabil, 63, 1-3.

Veronelli,M.; Mauro, M. and Bresadola, S. (1999), Influence of thermal dehydrochlorination on the photoxidation kinetics of PVC samples. Polym. Degrad. Stabil., 66, 349-357.

Yavuz, H. (2002), Preparation and degradation of Llactide and $\varepsilon$-caprolactone homo e copolymer films. Polym. Degrad. Stabil., 75, 431-437.

Received: May 27, 2003; Revised: January 13, 2004; Accepted: November 22, 2004. 